\title{
Compressibility and Dissolution Characteristics of Mixed Fruit Tablets Made from Guava and Pitaya Fruit Powders.
}

\begin{abstract}
This study reports the tableting of whole fruit powder from pitaya and guava and their dissolution in relation to use as drink's tablets. Pulps of both fruits with peels and seeds were freeze-dried into powders with addition of $10 \%$ maltodextrin. The fruit powders, individually as well as in a binary mixture (1:1), were analyzed for material properties and were found to be poor in flow. Among the three powders, guava powder attained the lowest density during compaction and exhibited as a poor compressible powder. Mixed fruit tablets containing $1 \%$ effervescent agent eroded quite fast in all three types of solvents studied. However, the acidic solvent $(0.1 \mathrm{~N} \mathrm{HCl})$ was found to be not suitable for erosion of tablets containing polyvinypolypyrrolidone (Kollidon CL). In terms of active ingredient release (antioxidant), Kollindon CL was found to be the best. In the case of color release (a $\square$ ), the faster the erosion, the better was the color intensity irrespective of dissolution media. As drink tablets, the mixture containing $10 \%$ sugar was highly preferred by majority of panelists (80\%). A month long storage study with the mixed fruit tablet formulation at room temperature showed good microbial stability.
\end{abstract}

Keyword: Compaction; Dissolution; Fruit powder; Fruit tablet; Vitamin C; Antioxidant 